\title{
openheart Association of hypertension with mortality in patients hospitalised with COVID-19
}

Kunwardeep S Bhatia, ${ }^{1}$ Hari P Sritharan, ${ }^{1}$ Jonathan Ciofani, ${ }^{1}$ Justin Chia (D) ${ }^{1}$ Usaid K Allahwala (D) , ${ }^{1}$ Karina Chui, ${ }^{1}$ Daniel Nour, ${ }^{1}$ Sheran Vasanthakumar, ${ }^{2}$ Dhanvee Khandadai, ${ }^{3}$ Pavithra Jayadeva, ${ }^{4}$ Rohan Bhagwandeen, ${ }^{5}$ David Brieger, ${ }^{6}$ Christopher Choong, ${ }^{1}$ Anthony Delaney, ${ }^{7}$ Girish Dwivedi, ${ }^{8,9}$ Benjamin Harris, ${ }^{10}$ Graham Hillis (D) , ${ }^{3}$ Bernard Hudson, ${ }^{11}$ George Javorski, ${ }^{12}$ Nigel Jepson, ${ }^{13}$ Logan Kanagaratnam, ${ }^{1}$ George Kotsiou, ${ }^{14}$ Astin Lee, ${ }^{15}$ Sidney T Lo, ${ }^{16}$ Andrew I Maclsaac, ${ }^{17}$ Brendan McQuillan, ${ }^{18}$ Isuru Ranasinghe, ${ }^{19,20}$ Antony Walton, ${ }^{21}$ James Weaver, ${ }^{22}$ William Wilson, ${ }^{4}$ Andy S C Yong, ${ }^{23}$ John Zhu, ${ }^{24}$ William Van Gaal, ${ }^{25}$ Leonard Kritharides, ${ }^{6}$ Clara K Chow (i) , ${ }^{26,27}$ Ravinay Bhindi ${ }^{1}$

- Additional supplemental material is published online only. To view, please visit the journal online (http://dx.doi.org/10. 1136/openhrt-2021-001853).

To cite: Bhatia KS, Sritharan HP, Ciofani J, et al. Association of hypertension with mortality in patients hospitalised with COVID-19. Open Heart 2021;8:e001853. doi:10.1136/ openhrt-2021-001853

Received 9 September 2021 Accepted 15 November 2021

Check for updates

(c) Author(s) (or their employer(s)) 2021. Re-use permitted under CC BY-NC. No commercial re-use. See rights and permissions. Published by BMJ.

For numbered affiliations see end of article.

\section{Correspondence to} Dr Kunwardeep S Bhatia; kunwardeep.bhatia@health. nsw.gov.au

\section{ABSTRACT}

Objective To assess whether hypertension is an independent risk factor for mortality among patients hospitalised with COVID-19, and to evaluate the impact of ACE inhibitor and angiotensin receptor blocker (ARB) use on mortality in patients with a background of hypertension. Method This observational cohort study included all index hospitalisations with laboratory-proven COVID-19 aged $\geq 18$ years across 21 Australian hospitals. Patients with suspected, but not laboratory-proven COVID-19, were excluded. Registry data were analysed for inhospital mortality in patients with comorbidities including hypertension, and baseline treatment with ACE inhibitors or ARBs.

Results 546 consecutive patients $(62.9 \pm 19.8$ years old, $51.8 \%$ male) hospitalised with COVID-19 were enrolled. In the multivariable model, significant predictors of mortality were age (adjusted OR (aOR) 1.09, 95\% Cl 1.07 to 1.12 , $\mathrm{p}<0.001$ ), heart failure or cardiomyopathy (aOR 2.71 , $95 \% \mathrm{Cl} 1.13$ to $6.53, \mathrm{p}=0.026)$, chronic kidney disease (aOR 2.33, 95\% Cl 1.02 to 5.32, $\mathrm{p}=0.044$ ) and chronic obstructive pulmonary disease (aOR $2.27,95 \% \mathrm{Cl} 1.06$ to $4.85, p=0.035)$. Hypertension was the most prevalent comorbidity (49.5\%) but was not independently associated with increased mortality (aOR 0.92, 95\% Cl 0.48 to 1.77, $\mathrm{p}=0.81$ ). Among patients with hypertension, ACE inhibitor (aOR 1.37, 95\% $\mathrm{Cl} 0.61$ to $3.08, \mathrm{p}=0.61$ ) and ARB (aOR $0.64,95 \% \mathrm{Cl} 0.27$ to $1.49, \mathrm{p}=0.30$ ) use was not associated with mortality.

Conclusions In patients hospitalised with COVID-19, preexisting hypertension was the most prevalent comorbidity but was not independently associated with mortality. Similarly, the baseline use of ACE inhibitors or ARBs had no independent association with in-hospital mortality.

\section{BACKGROUND}

By the end of January 2021, SARS-CoV-2, the causative virus of COVID-19, had infected

\section{Key questions}

What is already known about this subject?

- Conflicting data have been presented on the impact of hypertension, ACE inhibitors and angiotensin receptor blockers (ARBs) on mortality in hospitalised patients with COVID-19. There is a dearth of literature exploring these outcomes within both a generalisable population and a healthcare system that have not been overwhelmed by the pandemic.

What does this study add?

- In this multicentre analysis of 21 Australian hospitals, neither hypertension nor treatment with ACE inhibitors or ARBs was independently associated with mortality. By comparison, factors commonly associated with hypertension such as increasing age, heart failure or cardiomyopathy, chronic kidney disease and chronic obstructive pulmonary disease were predictors of mortality.

How might this impact on clinical practice?

- Clinicians should be aware that among patients hospitalised with COVID-19, pre-existing hypertension and treatment with ACE inhibitors or ARBs do not portend an increased risk of mortality.

over 100 million and killed over 2 million people internationally. ${ }^{1}$ Hypertension has been recognised as the most common comorbidity among patients hospitalised with COVID-19. ${ }^{2-4}$ However, it remains unclear whether hypertension is an independent risk factor for mortality or whether the presence of hypertension is a marker of other factors that confer an adverse prognosis such as advanced age, coronary artery disease, heart failure and renal disease. This has important implications for identifying patients at high 
risk of adverse outcomes and for prioritising the management of comorbidities in patients with and at risk of COVID-19. The primary aim of this study was therefore to assess whether hypertension is independently linked with increased mortality from COVID-19.

Additionally, there has been conjecture about the effects of ACE inhibitors and angiotensin receptor blockers (ARBs) on COVID-19 prognosis in light of the fact that the virus responsible for COVID-19, SARS-CoV-2, binds to the ACE2 receptor in order to enter host cells. ${ }^{5}$ With the potential upregulation of ACE2, secondary to ACE inhibitor and ARB use,${ }^{67}$ there exists a possible risk of increased viral entry into host cells. However, on the other hand, previous animal studies have suggested that ACE2 may have protective effects against acute respiratory distress syndrome. ${ }^{8}$ Initial observational data on this matter have been conflicting. ${ }^{910}$ Therefore, the secondary aim of this study was to assess the impact of ACE inhibitors and ARBs on mortality in patients with a background of hypertension admitted to hospital with COVID-19.

Australia provides a unique context to investigate these questions. Healthcare resources have been overwhelmed internationally, ${ }^{11-13}$ requiring stricter rationalisation of access to intensive care units (ICUs) in many regions and rapid construction of new hospitals in some settings. The extent to which this pandemic context has confounded the results of international clinical studies investigating COVID-19 outcomes is unknown. Australia has maintained control of COVID-19 case numbers such that hospital systems been able to maintain a high level of supportive care to all patients as required. The current manuscript presents analysis of the Australian Cardiovascular COVID-19 (AUS-COVID) Registry, which is the largest Australian multicentre COVID-19 cardiovascular registry of hospitalised patients.

\section{METHODS}

\section{Trial oversight}

The AUS-COVID Registry is a collaboration between 21 hospitals across Australia and was designed and overseen by a steering committee. The protocol and case report form are available online at https://wwwaus-covidcom. The registry was prospectively registered with the Australian and New Zealand Clinical Trials Registry (ACTRN12620000486921).

\section{Patients}

The registry included all index hospitalisations of consecutive patients aged 18 years or older with laboratoryproven SARS-CoV-2 infection entered in the AUS-COVID Registry by 22 January 2021. Patients with suspected but not laboratory-proven SARS-CoV-2 infection were excluded. Patients were also excluded if their medical or medication history was not available or if they were transferred to another hospital in which case mortality outcomes were not available. Given that many of the included sites were major tertiary centres, patients transferred from another hospital were excluded to avoid recruitment bias.

\section{Outcomes}

The registry captured over 150 datapoints extracted from the patient's medical record covering demographics, baseline comorbidities, baseline medications, laboratory results, treatment and outcomes. Potential variables for inclusion were age, sex, hypertension, coronary artery disease, heart failure or cardiomyopathy, atrial fibrillation or flutter, severe valvular disease, stroke or transient ischaemic attack (TIA), hypercholesterolaemia, diabetes mellitus, peripheral arterial disease, current or recent smoker ( $<1$ year), chronic obstructive pulmonary disease (COPD), asthma and chronic kidney disease (estimated glomerular filtration rate $($ eGFR $)<60 \mathrm{~mL} / \mathrm{min} / 1.73 \mathrm{~m}^{2}$ ). Coronary artery disease was defined as the presence of prior myocardial infarction, percutaneous coronary intervention, coronary artery bypass grafting, angina or $>50 \%$ stenosis of an epicardial vessel on CT coronary angiogram or invasive angiography based on available data on the electronic medical record. Other comorbidities were based on the documented medical history available from electronic and paper medical records.

\section{Statistical analysis}

Continuous variables were reported as mean (SD). Categorical variables were presented as proportions. Independent samples t-test was used to compare between group differences for normally distributed continuous variables. Pearson's $\mathrm{X}^{2}$ test and Fisher's exact test were used to compare proportions between groups for categorical variables when expected cell sizes were $\geq 5$ and $<5$, respectively. Multivariable binary logistic regression was performed to calculate adjusted ORs (aORs) for mortality. Potential variables were included in the multivariable model if they had a $p$ value of $<0.1$ in the univariable model. A secondary analysis was performed in patients with pre-existing hypertension, with the use of an ACE inhibitor or ARB on admission as additional variables. Statistical analysis was performed using IBM SPSS Statistics Subscription (V.1.0.0.1508). Results were considered statistically significant if the two-sided $p$ value was $<0.05$.

\section{Patient and public involvement}

Patients or the public were not involved in the design, or conduct, or reporting, or dissemination plans of our research.

\section{RESULTS}

Six hundred twenty-one patients were admitted with SARS-CoV-2 infection across 21 Australian hospitals. Five hundred forty-six patients were eligible for inclusion in the primary analysis. Ten patients were excluded because they were transferred to another hospital and a further 65 patients were excluded because their medical or medication history was not available.(figure 1) 
Consecutive patients admitted with COVID-19 to one of 21 Australian hospitals $(n=621)$

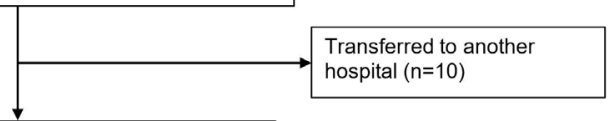

Consecutive patients admitted with COVID-19 who stayed at original hospital $(n=611)$

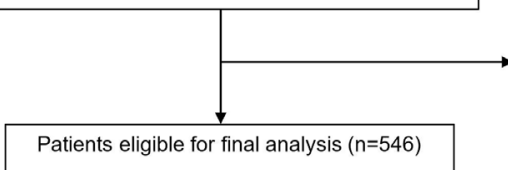

Medical history or

medication history not

available $(n=65)$

Figure 1 STROBE flow diagram of study population. Patient selection flow diagram. Five hundred and forty-six patients were eligible for final analysis out of 621 consecutively admitted patients. STROBE, Strengthening the Reporting of Observational Studies in Epidemiology.

The mean age of included patients was $62.9( \pm 19.8)$ years. Two hundred and eighty-three $(51.8 \%)$ patients were male, $92(16.8 \%)$ were nursing home residents and $35(6.4 \%)$ were healthcare workers. Baseline comorbidities are presented in table 1. Two-hundred and seventy $(49.5 \%)$ patients had a history of hypertension, 158
(28.9\%) had hypercholesterolaemia, 143 (26.2\%) had diabetes mellitus, $64(11.7 \%)$ had coronary artery disease and $46(8.4 \%)$ had chronic kidney disease.

Ninety-nine $(18.1 \%)$ patients were admitted to the ICU; $56(10.3 \%)$ patients were intubated; 81 (14.8\%) patients died in hospital.

Hypertension was more common in patients who died (71.6\% vs $45.6 \%, \mathrm{p}<0.001)$, as was advanced age $(81.7$ vs 59.6 years, $\mathrm{p}<0.001)$, coronary artery disease $(25.9 \%$ vs $9.2 \%, \mathrm{p}<0.001)$, heart failure or cardiomyopathy $(22.2 \%$ vs $3.7 \%, \mathrm{p}<0.001)$, stroke or TIA $(17.3 \%$ vs $5.6 \%, \mathrm{p}<0.001)$, atrial fibrillation or flutter $(19.8 \%$ vs $8.2 \%, \mathrm{p}=0.004)$, severe valvular disease $(6.2 \%$ vs $1.7 \%, \mathrm{p}=0.031)$, diabetes mellitus (40.7\% vs $23.7 \%$, $\mathrm{p}=0.002$ ), COPD (21.0 vs $6.2 \%$, $\mathrm{p}<0.001)$ and chronic kidney disease $(21.0$ vs $6.2 \%$, $\mathrm{p}<0.001)$. Sex was not significantly different between patients who died and those who survived (male $53.1 \%$ vs $51.6 \%, \mathrm{p}=0.81$ ).

The unadjusted ORs from the univariable binary logistic regression are presented in table 2 . Hypertension had an unadjusted OR of 3.01 (95\% CI 1.80 to $5.04, \mathrm{p}<0.001$ ) for in-hospital mortality. Other variables that were significant

Table 1 Baseline demographics and comorbidities on admission

\begin{tabular}{|c|c|c|c|c|}
\hline & All patients $(n=546)$ & Discharged $(n=465)$ & Deceased $(n=81)$ & $P$ value \\
\hline Mean age (SD), years & $62.9(19.8)$ & $59.6(19.1)$ & $81.7(11.3)$ & $<0.001$ \\
\hline Male, no (\%) & $283(51.8)$ & $240(51.6)$ & $43(53.1)$ & 0.811 \\
\hline Healthcare worker, no (\%) & $35(6.4)$ & $34(7.3)$ & $1(1.2)$ & 0.046 \\
\hline Nursing home resident, no (\%) & $92(16.8)$ & $56(12.0)$ & $36(44.4)$ & $<0.001$ \\
\hline Hypertension, no (\%) & $270(49.5)$ & $212(45.6)$ & $58(71.6)$ & $<0.001$ \\
\hline Coronary artery disease, no (\%) & $64(11.7)$ & $43(9.2)$ & $21(25.9)$ & $<0.001$ \\
\hline Heart failure or cardiomyopathy, no (\%) & $35(6.4)$ & $17(3.7)$ & $18(22.2)$ & $<0.001$ \\
\hline Atrial fibrillation or flutter, no (\%) & $54(9.9)$ & $38(8.2)$ & $16(19.8)$ & 0.004 \\
\hline Severe valvular disease, no (\%) & $13(2.4)$ & $8(1.7)$ & $5(6.2)$ & 0.031 \\
\hline Stroke or transient ischaemic attack, no (\%) & $40(7.3)$ & $26(5.6)$ & $14(17.3)$ & $<0.001$ \\
\hline Hypercholesterolaemia, no (\%) & $158(28.9)$ & $128(27.5)$ & $30(37.0)$ & 0.086 \\
\hline Diabetes mellitus, no (\%) & $143(26.2)$ & $110(23.7)$ & $33(40.7)$ & 0.002 \\
\hline Peripheral arterial disease, no (\%) & $7(1.3)$ & $5(1.1)$ & $2(2.5)$ & 0.279 \\
\hline Current or recent smoker (<1 year), no (\%) & $25(4.6)$ & $22(4.7)$ & $3(3.7)$ & 1.000 \\
\hline Chronic obstructive pulmonary disease, no (\%) & $46(8.4)$ & $29(6.2)$ & $17(21.0)$ & $<0.001$ \\
\hline Asthma, no (\%) & $63(11.5)$ & $57(12.3)$ & $6(7.4)$ & 0.259 \\
\hline Chronic kidney disease (eGFR $\left.<60 \mathrm{~mL} / \mathrm{min} / 1.73 \mathrm{~m}^{2}\right)$, no (\%) & $46(8.4)$ & $29(6.2)$ & $17(21.0)$ & $<0.001$ \\
\hline ACE inhibitor, no (\%) & $85(15.6)$ & $61(13.1)$ & $24(29.6)$ & $<0.001$ \\
\hline ARB, no (\%) & $109(20.0)$ & $94(20.2)$ & $15(18.5)$ & 0.880 \\
\hline Mineralocorticoid receptor antagonist, no (\%) & $18(3.3)$ & $13(2.8)$ & $5(6.2)$ & 0.166 \\
\hline Loop diuretic, no (\%) & $63(11.5)$ & $36(7.7)$ & $27(33.3)$ & $<0.001$ \\
\hline Thiazide diuretic, no (\%) & $39(7.1)$ & $31(6.7)$ & $8(9.9)$ & 0.347 \\
\hline Beta blocker, no (\%) & $86(15.8)$ & $62(13.3)$ & $24(29.6)$ & $<0.001$ \\
\hline Non-dihydropyridine calcium channel blocker, no (\%) & $7(1.3)$ & $6(1.3)$ & $1(1.2)$ & 1.000 \\
\hline Dihydropyridine calcium channel blocker, no (\%) & $84(15.4)$ & $71(15.3)$ & $13(16.0)$ & 0.868 \\
\hline
\end{tabular}

ARB, angiotensin receptor blocker; eGFR, estimated glomerular filtration rate. 


\begin{tabular}{llr}
\hline $\begin{array}{l}\text { Table } 2 \\
\text { baseline characteristics }\end{array}$ & \multicolumn{3}{l}{ Unadjusted ORs for in-hospital mortality by } \\
\hline Variable & $1.101(1.075$ to 1.127$)$ & $<0.001$ \\
\hline Age, years & $1.061(0.661$ to 1.702$)$ & 0.807 \\
\hline Male & $3.009(1.796$ to 5.043$)$ & $<0.001$ \\
\hline Hypertension & $3.435(1.908$ to 6.182$)$ & $<0.001$ \\
\hline Coronary artery disease & $7.529(3.689$ to 15.367$)$ & $<0.001$ \\
\hline Heart failure or cardiomyopathy & $2.766(1.459$ to 5.244$)$ & 0.002 \\
\hline Atrial fibrillation or flutter & $3.758(1.198$ to 11.791$)$ & 0.023 \\
\hline Severe valvular disease & $3.528(1.754$ to 7.096$)$ & $<0.001$ \\
\hline Stroke or transient ischaemic attack & $1.549(0.944$ to 2.540$)$ & 0.083 \\
\hline Hypercholesterolaemia & $2.219(1.356$ to 3.629$)$ & 0.002 \\
\hline Diabetes mellitus & $2.329(0.444$ to 12.214$)$ & 0.317 \\
\hline Peripheral arterial disease & $0.774(0.226$ to 2.650$)$ & 0.684 \\
\hline Current or recent smoker & $3.994(2.077$ to 7.678$)$ & $<0.001$ \\
\hline $\begin{array}{l}\text { Chronic obstructive pulmonary } \\
\text { disease }\end{array}$ & $0.573(0.238$ to 1.376$)$ & 0.213 \\
\hline Asthma & $3.994(2.077$ to 7.678$)$ & $<0.001$ \\
\hline $\begin{array}{l}\text { Chronic kidney disease (eGFR } \\
\left.<60 \text { mL/min/1.73 m }{ }^{2}\right)\end{array}$ & & \\
\hline
\end{tabular}

eGFR, estimated glomerular filtration rate.

on the univariable analysis were age (OR $1.10,95 \% \mathrm{CI}$ 1.08 to $1.13, \mathrm{p}<0.001)$, coronary artery disease (OR 3.44 , $95 \%$ CI 1.91 to $6.18, \mathrm{p}<0.001$ ), heart failure or cardiomyopathy (OR 7.53, 95\% CI 3.69 to $15.37, \mathrm{p}<0.001$ ), atrial fibrillation or flutter (OR 2.77, 95\% CI 1.46 to 5.24, $\mathrm{p}=0.002$ ), severe valvular disease (OR 3.76, 95\% CI 1.20 to $11.79, \mathrm{p}=0.023$ ), stroke or TIA (OR 3.53, 95\% CI 1.75 to 7.10, $\mathrm{p}<0.001$ ), diabetes mellitus (OR 2.22, 95\% CI 1.36 to $3.63, \mathrm{p}=0.002$ ), COPD (OR $3.99,95 \%$ CI 2.08 to 7.68 , $\mathrm{p}<0.001)$ and chronic kidney disease (OR 3.99, 95\% CI 2.08 to $7.68, \mathrm{p}<0.001)$.

The multivariable binary logistic regression model was statistically significant $\left(\chi^{2}(11)=136.22, p<0.001\right)$. The model correctly classified $85.3 \%$ of cases. In the multivariable model, age (aOR 1.09, 95\% CI 1.07 to 1.12 , $\mathrm{p}<0.001$ ), heart failure or cardiomyopathy (aOR 2.71, $95 \%$ CI 1.13 to $6.53, \mathrm{p}=0.026$ ), chronic kidney disease (aOR 2.33, 95\% CI 1.02 to 5.32, $\mathrm{p}=0.044$ ) and COPD (aOR 2.27, 95\% CI 1.06 to $4.85, \mathrm{p}=0.035$ ) were associated with an increased risk of mortality. Hypertension was not independently associated with increased mortality (aOR $0.92,95 \%$ CI 0.48 to $1.77, \mathrm{p}=0.81$ ). (figure 2 ) (table 3 )

A secondary analysis was performed on the 270 patients with pre-existing hypertension. The mean age of these patients was $72.7( \pm 14)$ years (online supplemental table 1). Fifty-eight (21.5\%) patients died. The use of an ARB was less common in patients who died $(20.7 \%$ vs $41.5 \%, p=0.004)$. There was no difference in use of ACE inhibitors in those who died compared with those who survived $(29.3 \%$ vs $25.5 \%, \mathrm{p}=0.61)$. In the multivariable binary logistic regression model, ACE inhibitor (aOR 1.37, 95\% CI 0.61 to 3.08, $\mathrm{p}=0.61$ ) and ARB (aOR 0.64, $95 \%$ CI 0.27 to $1.49, \mathrm{p}=0.30$ ) use was not associated with increased mortality (online supplemental table 3).

\section{DISCUSSION}

\section{Hypertension}

In this multicentre registry of over 500 consecutive patients hospitalised with COVID-19, hypertension was the most prevalent cardiovascular comorbidity. We found that hypertension was associated with increased mortality

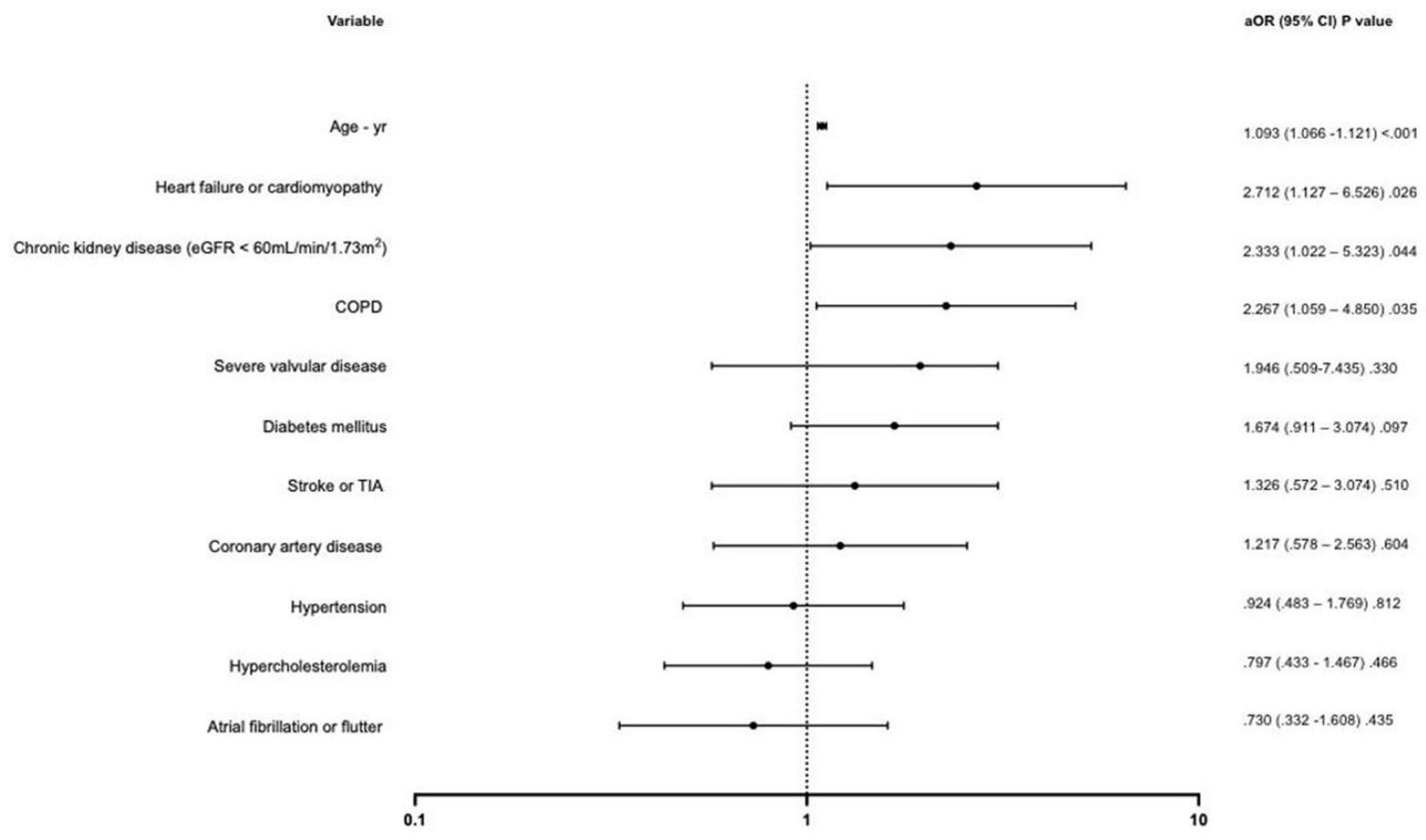

Figure 2 Forrest plot of multivariable logistic regression for in-hospital mortality by baseline characteristics. Adjusted ORs (aORs) for in-hospital mortality derived from multivariable binary logistic regression. COPD, chronic obstructive pulmonary disease; eGFR, estimated glomerular filtration rate; TIA, transient ischaemic attack. 


\begin{tabular}{|c|c|c|}
\hline Variable & OR $(95 \% \mathrm{Cl})$ & $P$ value \\
\hline Age, years & $1.093(1.066$ to 1.121$)$ & $<0.001$ \\
\hline Hypertension & 0.924 (0.483 to 1.769$)$ & 0.812 \\
\hline Coronary artery disease & $1.217(0.578$ to 2.563$)$ & 0.604 \\
\hline Heart failure or cardiomyopathy & 2.712 (1.127 to 6.526$)$ & 0.026 \\
\hline Atrial fibrillation or flutter & 0.730 (0.332 to 1.608$)$ & 0.435 \\
\hline Severe valvular disease & 1.946 (0.509 to 7.435$)$ & 0.330 \\
\hline Stroke or transient ischaemic attack & $1.326(0.572$ to 3.074$)$ & 0.510 \\
\hline Hypercholesterolaemia & 0.797 (0.433 to 1.467$)$ & 0.466 \\
\hline Diabetes mellitus & 1.674 (0.911 to 3.074$)$ & 0.097 \\
\hline Chronic obstructive pulmonary disease & 2.267 (1.059 to 4.850$)$ & 0.035 \\
\hline $\begin{array}{l}\text { Chronic kidney disease (eGFR }<60 \mathrm{~mL} / \\
\min / 1.73 \mathrm{~m}^{2} \text { ) }\end{array}$ & 2.333 (1.022 to 5.323$)$ & 0.044 \\
\hline
\end{tabular}

eGFR, estimated glomerular filtration rate.

on univariable but not multivariable analysis, adjusted for age, sex and comorbidities. By comparison, cardiovascular factors commonly associated with hypertension such as age, heart failure or cardiomyopathy, chronic kidney disease and COPD were significant independent predictors of mortality.

In contrast, an early study from China found that hypertension was independently associated with a composite endpoint of ICU admission, mechanical ventilation and death (HR 1.58, 95\% CI 1.07 to 2.32, $\mathrm{p}=0.022$ ). ${ }^{2}$ However, the results should be interpreted with caution since the analysis only adjusted for age and smoking status. Furthermore, decisions around ICU admission and mechanical ventilation can be subjective and may therefore differ between geographical regions and may depend on the availability of limited healthcare resources.

A further retrospective observational study based in Wuhan, China also showed that hypertension was independently associated with in-hospital mortality, even after adjusting for confounders including but not limited to age, sex, cardiovascular diseases and COPD (HR 2.12, 95\% CI 1.17 to $3.82, p=0.013) .{ }^{14}$ This study, however, was based in a new emergency hospital constructed for the purpose of managing patients with COVID-19 and it is therefore unclear the extent to which these results are generalisable to the wider population treated in a nonpandemic healthcare system.

Consistent with results of our study, analysis of data from a multicentre US surveillance network for hospitalised patients with COVID-19 found that hypertension was neither associated with ICU admission (adjusted RR (aRR) $0.92,95 \%$ CI 0.79 to 1.07 ) nor death (aRR 1.07, $95 \%$ CI 0.79 to 1.45 ) after adjustment for demographic characteristics and comorbidities including age, sex, cardiovascular disease and chronic lung disease. ${ }^{15}$ Likewise, a study of individuals in the US Department of Veterans Affairs national healthcare system found that hypertension was not associated with mortality (adjusted
HR (aHR) $0.95,95 \%$ CI 0.81 to 1.12 ) after adjusting for confounders including sociodemographic characteristics, comorbidities and presenting symptoms. ${ }^{3}$ Notably, however, this study was restricted to the veteran affairs system and included a high proportion of male patients, constituting $91 \%$ of the cohort. Additionally, a twocentre prospective cohort study in New York found that hypertension was associated with in-hospital mortality on univariable but not multivariable analysis (aHR 1.58, $95 \%$ CI 0.89 to 2.81) after adjusting for demographic factors and comorbidities including advanced age, sex, duration of symptoms prior to hospitalisation, cardiovascular disease and chronic lung disease. ${ }^{4}$ A further large retrospective study based in New York similarly found that hypertension was not associated with in-hospital mortality on multivariable analysis (aOR $0.84,95 \%$ CI 0.65 to 1.10 , $\mathrm{p}=0.214){ }^{16}$

\section{ACE inhibitors and ARBs}

There has been conjecture in the literature about the effect of ACE inhibitors and ARBs on COVID-19 prognosis. In the present study, multivariable analysis demonstrated no evidence of harm from use of ACE inhibitors or ARBs, which corresponds to much of the existing literature on this topic. One study based in France did, however, show that use of ACE inhibitors or ARBs was associated with higher risk of admission to ICU or death before ICU admission. ${ }^{10}$ This study was notably in a particularly elderly and unwell cohort of patients, with a median age of 73 years and mortality of $23.5 \%$ with 23 patients still in ICU at the time of analysis. In contrast, a study based in Hubei Province, China showed that after adjusting for age, gender, comorbidities and in-hospital medications, patients taking ACE inhibitors or ARBs had lower rates of all-cause mortality compared with those not taking these medications (HR 0.42, 95\% CI 0.19 to 0.92 , $\mathrm{p}=0.03) .{ }^{9}$ Similarly, in a large cohort from the French national health data system, it was found that ACE inhibitors and ARBs were each associated with lower risk of intubation or death compared with individuals using calcium channel blockers for hypertension. Furthermore, a randomised controlled trial of patients hospitalised with mild-to-moderate severity COVID-19 in Brazil showed no significant difference between continuation versus discontinuation of ACE inhibitors or ARBs on mortality. ${ }^{17}$

\section{Other comorbidities}

Consistent with our results, advanced age, COPD and chronic kidney disease have previously been shown to be robust predictors of adverse prognosis. ${ }^{3415}$ However, the relationship between heart failure and mortality among patients hospitalised with COVID-19 has been less robustly characterised. The results of our study confirm the findings of a retrospective analysis of hospitalised patients in the USA which found that heart failure was an independent predictor of mortality (aOR 1.88, 95\% CI 1.27 to $2.78, \mathrm{p}=0.002) .{ }^{16}$ This emphasises the need to 
classify patients with pre-existing heart failure as a highrisk group and prioritise them in vaccine programmes.

\section{Limitations}

The AUS-COVID Registry does not include information about race and contains insufficient data on body mass index to include these potentially significant confounders in the multivariable model. The study also does not address questions about the interaction of poorly controlled hypertension and mortality. Furthermore, the registry reports on mortality during index hospitalisation only and no long-term outcome data are available. Despite these limitations, the AUS-COVID Registry is the first and largest multicentre Australian registry focused on cardiovascular comorbidities among patients hospitalised with COVID-19 and therefore provides important insights into the risk factors for adverse prognosis.

\section{CONCLUSION}

In patients hospitalised with COVID-19, a history of COPD, heart failure or cardiomyopathy, chronic kidney disease and advanced age were independent risk factors for mortality. While hypertension was the most prevalent cardiovascular comorbidity, it was not independently associated with mortality. Similarly, the baseline use of ACE inhibitors or ARBs had no independent association with in-hospital mortality.

\section{Author affiliations}

${ }^{1}$ Cardiology, Royal North Shore Hospital, St Leonards, New South Wales, Australia

${ }^{2}$ Cardiology, Northern Hospital Epping, Epping, Victoria, Australia

${ }^{3}$ Department of Cardiology, Royal Perth Hospital, Perth, Western Australia, Australia

${ }^{4}$ Cardiology, The Royal Melbourne Hospital, Melbourne, Victoria, Australia

${ }^{5}$ Cardiology, John Hunter Hospital, New Lambton Heights, New South Wales, Australia

${ }^{6}$ Cardiology, Concord Repatriation General Hospital, Concord, New South Wales, Australia

${ }^{7}$ Intensive Care, Royal North Shore Hospital, St Leonards, New South Wales, Australia

${ }^{8}$ Cardiology, Harry Perkins Institute of Medical Research, Perth, Australian Capital Territory, Australia

${ }^{9}$ Department of Advanced Clinical and Translational Cardiovascular Imaging, Harry Perkins Institute of Medical Research, Perth, Western Australia, Australia

${ }^{10}$ Respiratory and Sleep Medicine, Royal North Shore Hospital, St Leonards, New South Wales, Australia

${ }^{11}$ NSW Health Pathology, Royal North Shore Hospital, St Leonards, New South Wales, Australia

${ }^{12}$ Cardiology, The Prince Charles Hospital, Chermside, Queensland, Australia

${ }^{13}$ Cardiology, Prince of Wales Hospital and Community Health Services, Randwick, New South Wales, Australia

${ }^{14}$ Infectious Diseases and Microbiology, Royal North Shore Hospital, St Leonards, New South Wales, Australia

${ }^{15}$ Cardiology, Wollongong Hospital, Wollongong, New South Wales, Australia

${ }^{16}$ Cardiology, University of New South Wales, Liverpool Hospital, Liverpool, New South Wales, Australia

${ }^{17}$ Cardiology Department, St Vincent's Health Australia, Sydney, New South Wales, Australia

${ }^{18} \mathrm{~S} c h o o l$ of Medicine and Pharmacology, University of Western Australia, Crawley, Western Australia, Australia

${ }^{19}$ Cardiology, The University of Queensland, Saint Lucia, Queensland, Australia

${ }^{20}$ The Prince Charles Hospital, Chermside, Queensland, Australia

${ }^{21}$ Cardiology, Alfred Hospital, Melbourne, Victoria, Australia
${ }^{22}$ Cardiology, Royal Prince Alfred Hospital, Camperdown, New South Wales, Australia

${ }^{23}$ Cardiology, Concord Hospital, Sydney, New South Wales, Australia

${ }^{24}$ Cardiology, Lismore Base Hospital, Lismore, New South Wales, Australia

${ }^{25}$ Northern Health NCHER, Epping, Victoria, Australia

${ }^{26}$ Sydney Medical School, The University of Sydney, Sydney, New South Wales, Australia

${ }^{27}$ Cardiology, The George Institute for Global Health, Sydney, New South Wales, Australia

Contributors All listed authors contributed to interpretation of data as well as drafting and revision of the manuscript for this study. KB, HS, WVG, LK, CKC and $\mathrm{RB}$ were responsible for the study design and acted as the steering committee. Statistical analysis was conducted by KB, HS, JCiofani and JChia, KB is responsible for the overall content of this article as guarantor.

Funding This study is supported by unrestricted grants from the Paul Ramsay Foundation and the Northern Sydney Local Health District.

Competing interests None declared.

Patient consent for publication Not required.

Ethics approval The AUS-COVID Registry was approved by the Northern Sydney Local Health District Human Research Ethics Committee (HREC 2020/ETH00732), which granted a waiver of consent.

Provenance and peer review Not commissioned; internally peer reviewed.

Data availability statement Data are available upon reasonable request.

Open access This is an open access article distributed in accordance with the Creative Commons Attribution Non Commercial (CC BY-NC 4.0) license, which permits others to distribute, remix, adapt, build upon this work non-commercially, and license their derivative works on different terms, provided the original work is properly cited, appropriate credit is given, any changes made indicated, and the use is non-commercial. See: http://creativecommons.org/licenses/by-nc/4.0/.

\section{ORCID iDs}

Justin Chia http://orcid.org/0000-0002-5357-429X

Usaid K Allahwala http://orcid.org/0000-0001-7178-4744

Graham Hillis http://orcid.org/0000-0003-2417-4673

Clara K Chow http://orcid.org/0000-0003-4693-0038

\section{REFERENCES}

1 WHO. Who coronavirus disease (COVID-19) Dashboard, 2021. Available: https://covid19. who.int/ [Accessed 31 Jan 2021].

2 Guan W-jie, Liang W-hua, Zhao Y, et al. Comorbidity and its impact on 1590 patients with COVID-19 in China: a nationwide analysis. Eur Respir J 2020;55:2000547.

3 loannou GN, Locke E, Green P, et al. Risk Factors for Hospitalization, Mechanical Ventilation, or Death Among 10131 US Veterans With SARS-CoV-2 Infection. JAMA Netw Open 2020;3:e2022310.

4 Cummings MJ, Baldwin MR, Abrams D, et al. Epidemiology, clinical course, and outcomes of critically ill adults with COVID-19 in New York City: a prospective cohort study. Lancet 2020;395:1763-70.

5 Zhou P, Yang X-L, Wang X-G, et al. A pneumonia outbreak associated with a new coronavirus of probable bat origin. Nature 2020;579:270-3.

6 Ferrario CM, Jessup J, Chappell MC, et al. Effect of angiotensinconverting enzyme inhibition and angiotensin II receptor blockers on cardiac angiotensin-converting enzyme 2. Circulation 2005;111:2605-10.

7 Deshotels MR, Xia H, Sriramula S, et al. Angiotensin II mediates angiotensin converting enzyme type 2 internalization and degradation through an angiotensin II type I receptor-dependent mechanism. Hypertension 2014;64:1368-75.

8 Imai Y, Kuba K, Rao S, et al. Angiotensin-converting enzyme 2 protects from severe acute lung failure. Nature 2005;436:112-6.

9 Zhang P, Zhu L, Cai J, et al. Association of inpatient use of angiotensin-converting enzyme inhibitors and angiotensin II receptor blockers with mortality among patients with hypertension hospitalized with COVID-19. Circ Res 2020;126:1671-81.

10 Liabeuf S, Moragny J, Bennis Y, et al. Association between reninangiotensin system inhibitors and COVID-19 complications. Eur Heart J Cardiovasc Pharmacother 2021;7:426-434. 
11 Tanne JH, Hayasaki E, Zastrow M, et al. Covid-19: how doctors and healthcare systems are tackling coronavirus worldwide. BMJ 2020;368:m1090.

12 Paterlini M. On the front lines of coronavirus: the Italian response to covid-19. BMJ 2020;368:m1065.

13 Yager PH, Whalen KA, Cummings BM. Repurposing a pediatric ICU for adults. N Engl J Med 2020;382:e80.

14 Gao C, Cai Y, Zhang K, et al. Association of hypertension and antihypertensive treatment with COVID-19 mortality: a retrospective observational study. Eur Heart J 2020;41:2058-66.

15 Kim L, Garg S, O'Halloran A, et al. Risk Factors for Intensive Care Unit Admission and In-hospital Mortality Among Hospitalized Adults
Identified through the US Coronavirus Disease 2019 (COVID-19)Associated Hospitalization Surveillance Network (COVID-NET). Clin Infect Dis 2021;72:e206-14.

16 Alvarez-Garcia J, Lee S, Gupta A, et al. Prognostic Impact of Prior Heart Failure in Patients Hospitalized With COVID-19. J Am Coll Cardiol 2020;76:2334-48.

17 Lopes RD, Macedo AVS, de Barros E Silva PGM, et al. Effect of discontinuing vs continuing angiotensin-converting enzyme inhibitors and angiotensin II receptor blockers on days alive and out of the hospital in patients admitted with COVID-19: a randomized clinical trial. JAMA 2021;325:254-64. 